\title{
New diagnostic strategy for sepsis-induced disseminated intravascular coagulation: a prospective single-center observational study
}

\author{
Hiroyasu Ishikura*, Takeshi Nishida, Akira Murai, Yoshihiko Nakamura, Yuhei Irie, Junichi Tanaka and Takehiro Umemura
}

\begin{abstract}
Introduction: Inflammation and coagulation are closely interrelated pathophysiologic processes in the pathogenesis of sepsis. However, the diagnostic criteria of sepsis and disseminated intravascular coagulation (DIC) are different. This study aimed to define a biomarker panel to predict sepsis-induced DIC in emergency department patients.
\end{abstract}

Methods: Eighty-two patients who were admitted to the emergency department of a tertiary university hospital were included in this study. The inclusion criteria were as follows: (1) age $>18$ years; (2) $\geq 1$ systemic inflammatory response syndrome (SIRS) criteria. Patients were excluded if they lacked biomarker data or apparent clinical manifestations. Eleven biomarkers were assayed from blood drawn on ED admission. Receiver operating curve (ROC) analysis including the area under the ROC and multivariable logistic regression were used to identify an optimal combination of biomarkers to create a diagnostic panel. The derived formula for weighting biomarker values was used to determine the severity of sepsis-induced DIC, which was divided into three categories: mild, moderate, and severe. We also investigated the ability of this classification to predict secondary outcome measures of rates of sepsis and DIC, DIC score, acute physiology and chronic health evaluation (APACHE) II score, sequential organ failure score (SOFA) score, and 28-day all-cause mortality.

Results: Among the 11 biomarkers tested, the optimal 2-marker panel comprised presepsin and protein C. The area under the curve for the accuracies of predicting sepsis and DIC from these two biomarkers were 0.913 and 0.880 , respectively. When patients were divided according to the severity of sepsis-induced DIC, all secondary outcomes except for mortality were significantly higher depending on the severity $(P<.0001)$. The overall mortality rates of mild, moderate, and severe sepsis-induced DIC were $7.14 \%, 15.4 \%$, and $28.6 \%$, respectively $(P=.0994)$.

Conclusions: A biomarker panel of presepsin and protein $C$ is predictive of the severity of sepsis-induced DIC in suspected ED patients. These criteria for sepsis-induced DIC are very simple, easy to implement, and can be used in intensive care units as a point-of-care test.

\section{Introduction}

Sepsis is often a complication that occurs in the clinical course of medical and surgical patients treated for other diseases [1,2], and remains one of the most significant causes of mortality in intensive care units. The most recent international sepsis guidelines entitled "Surviving Sepsis Campaign: International Guidelines for Management of Severe Sepsis and Septic Shock: 2012" recommend early diagnosis and treatment of sepsis to avoid multiple organ failure and other adverse outcomes [3]. Sepsis is diagnosed

\footnotetext{
* Correspondence: ishikurah@fukuoka-u.ac.jp

Department of Emergency and Critical Care Medicine, Faculty of Medicine, Fukuoka University, 7-45-1 Nanakuma, Jonan-ku, Fukuoka 814-0180, Japan
}

based on evidence of infection along with the presence of systemic inflammatory response syndrome (SIRS) defined by the American College of Chest Physicians/Society of Critical Care Medicine (ACCP/SCCM) guidelines [4]. And sepsis was diagnosed when patients met the criteria for SIRS and an infectious source was documented or strongly suspected based on clinical presentation.

The majority of ill patients with SIRS present with coagulation abnormalities. Inflammation and coagulation play pivotal roles in the pathogenesis of sepsis. Evidence of extensive cross-talk between these two systems has been increasing [5]; inflammation leads to the activation of coagulation, which in turn considerably affects in- 
flammatory activity. Since infection-induced disseminated intravascular coagulation (DIC) is closely associated with SIRS in a considerable percentage of patients, patients who exhibit two or more SIRS criteria for more than three consecutive days are frequently associated with DIC [6]. Sepsis is the most common disease associated with DIC. Approximately 20 to $40 \%$ of all sepsis patients are complicated with DIC [7-10]. There are some standard care procedures for sepsis, including the use of antibiotics, oxygen, fluid resuscitation and corticosteroids [11]. However, the mortality rate is still within the range of 30 to $50 \%$ in patients with septic shock [12,13]. Gando et al. [6] reported that DIC is frequently associated with SIRS (83\%) and that such patients have a high mortality rate $(63 \%)$. Thus, the mortality rate of sepsis patients complicated with DIC is clearly higher than that of patients without DIC. Therefore, the early diagnosis and treatment of sepsis-induced DIC are critical for improving the prognosis.

However, there are different diagnostic systems and criteria for SIRS/sepsis and DIC. Furthermore, there are still no diagnostic criteria for sepsis-induced DIC, which may delay diagnosis and treatment initiation, and consequently be detrimental for the patient. Therefore, this study aimed to establish the diagnostic criteria for sepsis-induced DIC.

\section{Materials and methods}

This prospective single-center observational study was conducted at the Department of Emergency and Critical Care Medicine, Fukuoka University Hospital, Fukuoka, Japan - a 915-bed referral, tertiary hospital - from June 2010 to June 2011. This study was approved by the institutional ethics committee, and all participants provided informed consent prior to participation. Patients aged $\geq 18$ years who met one or more SIRS criteria were enrolled in this study. The background of these patients included liver cirrhosis, warfarin treatment, continuing antibiotics and/or steroid use, traumatic injury and others. We excluded patients who lacked a concentration of biomarkers or apparent clinical manifestations. Patients were evaluated for the presence of SIRS and sepsis according to the ACCP/SCCM guidelines [4]. The scoring system of the Japanese Association for Acute Medicine (JAAM) for DIC was used for the diagnosis of DIC in this study. This DIC diagnostic algorithm for scoring DIC includes the following variables: platelet count, prothrombin time, fibrin/fibrinogen degradation product level and SIRS criteria. The details of the algorithm have been published elsewhere [14]. DIC was defined by a score of $\geq 4$. Illness severity was evaluated according to the Acute Physiology and Chronic Health Evaluation (APACHE) II score [15]. The APACHE II score assesses the illness severity of critical patients admitted to intensive care units on the basis of routine physiologic measurements, age and previous health status. It is used to predict the outcome of critical illnesses. Organ failure was assessed according to the Sequential Organ Failure Assessment (SOFA) score [16]. The SOFA score estimates organ dysfunction related to various disease statuses, especially sepsis, and is calculated using readily available measurements to quantify the dysfunction of the six major organs. Furthermore, it is useful for evaluating the morbidity and mortality of critical illnesses. All patients were followed-up for 28 days after enrollment in the study, and 28-day all-cause mortality was assessed.

\section{Study procedures}

Blood samples for measuring the markers were collected on admission. Presepsin, procalcitonin (PCT), interleukin-6 (IL-6), C-reactive protein (CRP) and white blood cell (WBC) count were measured as inflammatory molecular markers in plasma. Antithrombin (AT), protein C (PC) activities, platelet count, prothrombin time (PT), D-dimer and thrombomodulin (TM) levels were measured as coagulation and fibrinolysis molecular markers. Platelet and $\mathrm{WBC}$ counts were measured in whole blood using an XT-1800i (Sysmex Co., Kobe, Japan). PT, D-dimer level, and $\mathrm{PC}$ and $\mathrm{AT}$ activities were measured in plasma using a Coapresta 2000 (Sekisui Medical, Tokyo, Japan). TM was measured using a STACIA (Mitsubishi Chemical Medience Corp., Tokyo, Japan). International normalized ratio (INR) was calculated using the following formula: $\mathrm{INR}=($ patient $\mathrm{PT} /$ normal PT $) \times \mathrm{ISI}$, where normal $\mathrm{PT}$ represents the average of mean normal $\mathrm{PT}$ range of the laboratory result and ISI is the International Sensitivity Index, which is the correction coefficient of thromboplastin in commercial kits calculated according to international reference samples.

\section{Presepsin assay}

Presepsin concentrations were measured using a compact automated immunoanalyzer, PATHFAST, based on a chemiluminescent enzyme immunoassay (CLEIA) (Mitsubishi Chemical Medience Corp., Japan) [17,18]. Whole blood was collected using a conventional blood collection tube (TERUMO, Tokyo, Japan) with EDTA-2 $\mathrm{K}$ as an anticoagulant and used as a sample within $4 \mathrm{~h}$ after collection.

\section{PCT assay}

PCT concentrations were measured by the Elecsys BRAHMS PCT assay (Roche Diagnostics, Tokyo, Japan) using EDTA plasma as a sample.

\section{Interleukin-6 assay}

IL-6 concentrations were measured using the Immulyze 2000 assay system (Siemens Healthcare Diagnostics, Tokyo, Japan) using EDTA plasma as a sample. 


\section{CRP assay}

CRP concentrations were measured by CRP-LATEX (II) X2 "SEIKEN" (Denka Seiken Co., Ltd., Tokyo, Japan) using EDTA plasma as a sample.

\section{Statistical analysis}

Unless otherwise indicated, all data are expressed as mean \pm standard deviation (SD). SPSS 15.0 J (SPSS Inc., Chicago, IL, USA) was used for all statistical analyses. Comparisons between the two groups were made using unpaired Students $t$-test and either the $\chi^{2}$ test or Fisher's exact test if necessary. Multiple datasets were analyzed by one-way ANOVA. The relationships between the measured variables and prognosis were analyzed by stepwise multiple logistic regression analysis with sepsis and/or DIC as the dependent variable. The results are reported as odds ratios (ORs) and 95\% confidence intervals (95\% CIs). Receiver-operating curve (ROC) analysis including the area under the ROC (AUC) was used to compare prognostic methods as predictors of sepsis and DIC. The standard error of the ROC was calculated using the formula based on Hanley and McNeil [19]. The level of significance was set at $P<.05$.

\section{Results}

\section{Population characteristics}

Of the 84 patients initially enrolled, we excluded 2 according to the exclusion criteria. Thus, a total of 82 patients were included in the analysis (Table 1). The mean age of the patients (44 men and 38 women) was $67.2 \pm 17.3$ years (median: 72.5 years, range: 21 to 93 years). Of all patients, 39 and 43 were diagnosed with non-sepsis and sepsis, respectively. In addition, 46 and 36 patients were classified into the non-DIC and DIC groups according to the JAAM DIC criteria, respectively. Furthermore, 26 patients with sepsis who met the JAAM DIC criteria were classified as having sepsis-induced DIC. The clinical characteristics of the 26 sepsis-induced DIC patients who met the sepsis and the JAAM DIC criteria were shown in Table 2.

Table 1 Patient backgrounds

\begin{tabular}{llll}
\hline Diagnosis & \multicolumn{2}{c}{ JAAM DIC } & Total \\
\cline { 2 - 3 } & Negative & Positive & \\
\hline Non-infection & 8 & 4 & 12 \\
SIRS & 15 & 4 & 19 \\
Infection & 6 & 2 & 8 \\
Sepsis & 5 & 3 & 8 \\
Severe sepsis & 4 & 10 & 14 \\
Septic shock & 8 & 13 & 21 \\
Total & 46 & 36 & 82 \\
\hline
\end{tabular}

DIC, disseminated intravascular coagulation; JAAM, Japanese Association for Acute Medicine; SIRS, systemic inflammatory response syndrome.
Table 2 Clinical characteristics of the 26 sepsis-induced DIC patients

\begin{tabular}{ll}
\hline Characteristics & Number of patients \\
\hline Respiratory & 10 \\
Intra- or retro-abdominal, or pelvic cavity & 9 \\
Soft tissue or bone & 4 \\
Urinary & 1 \\
Blood or catheter & 1 \\
Unknown & 1 \\
Total & 26 \\
\hline
\end{tabular}

DIC, disseminated intravascular coagulation.

\section{Biomarker distributions}

The means and SDs of coagulation and fibrinolysis molecular markers (AT and PC activities, platelet count, prothrombin time-international normalized ratio (PT-INR), and TM and D-dimer levels) and inflammatory molecular markers (presepsin, PCT, IL-6, CRP and WBC count) in patients with and without sepsis and DIC are shown in Tables 3 and 4, respectively. In addition, the AUC of each biomarker was calculated to evaluate the usefulness of each biomarker for the diagnoses of sepsis and DIC (Tables 3 and 4).

\section{Selection of a multi-marker panel and development of the sepsis-induced DIC diagnostic algorithm}

In this study, biomarkers with an AUC of $>0.8$ were selected as part of the optimal biomarker panel (Tables 3 and 4). Regarding the inflammatory biomarkers, only the AUC for presepsin exceeded 0.8. Meanwhile, among the coagulation and fibrinolysis molecular markers, the AUCs of AT and PC were $>0.8$. The coagulation and fibrinolysis molecular markers to identify DIC patients with a primary outcome of DIC on admission were selected by multivariate logistic regression analysis using AT and PC. As a result, PC was the only statistically significant prognostic factor of DIC (OR: 0.939, 95\% CI: 0.911 to $0.962 ; P<.0001)$. The following biomarkers were consequently found to compose the optimal biomarker panel: (1) presepsin (an inflammatory biomarker) and (2) PC (a coagulation marker). The AUCs for the combination of presepsin and $\mathrm{PC}$ in the patients with and without sepsis and DIC were 0.913 and 0.880 , respectively.

According to ROC analysis, the optimal cut-off values of presepsin and PC for the diagnosis of sepsis were $647 \mathrm{pg} / \mathrm{mL}$ and 47\%, respectively; those for the diagnosis of DIC were $899 \mathrm{pg} / \mathrm{mL}$ and 55\%, respectively (Table 5). The patients enrolled in this study were consequently divided into nine groups according to these cutoff values (Figure 1A).

Finally, we classified the patients into the following three groups according to presepsin concentration and PC activity: (1) severe $(\mathrm{n}=28)$, presepsin $>900 \mathrm{pg} / \mathrm{mL}$ and 
Table 3 Biomarkers in the whole population and stratified by the presence or absence of sepsis

\begin{tabular}{|c|c|c|c|c|c|}
\hline \multirow[t]{3}{*}{ Biomarker } & \multirow{3}{*}{$\begin{array}{l}\text { Normal } \\
\text { range }\end{array}$} & \multirow{3}{*}{$\begin{array}{l}\begin{array}{l}\text { Overall } \\
\text { population }\end{array} \\
\text { Mean (SD) }\end{array}$} & \multicolumn{3}{|c|}{ Sepsis } \\
\hline & & & Yes $(n=43)$ & No $(n=39)$ & ROC analysis \\
\hline & & & Mean (SD) & Mean (SD) & AUC \\
\hline \multicolumn{6}{|c|}{ Coagulation and fibrinolysis molecular markers } \\
\hline AT activity, \% & 80 to 130 & $71.9(28.1)$ & $57.0(23.9)$ & $88.2(23.4)^{* *}$ & 0.828 \\
\hline PC activity, \% & 70 to 150 & $55.2(34.6)$ & $36.4(24.5)$ & $75.9(32.7)^{* *}$ & 0.834 \\
\hline $\mathrm{TM}, \mathrm{U} / \mathrm{mL}$ & $<22$ & $6.02(6.19)$ & $8.37(7.91)$ & $3.67(2.00)^{* *}$ & 0.802 \\
\hline Platelet counts, $\times 10^{4} / \mathrm{\mu L}$ & 13.0 to 36.9 & $17.5(10.7)$ & $14.3(8.73)$ & $21.1(11.8)^{* *}$ & 0.681 \\
\hline PT-INR & 0.85 to 1.15 & $1.63(1.04)$ & $1.85(1.14)$ & $1.40(0.87)^{* *}$ & 0.795 \\
\hline D-dimer, ng/mL & $\leqq 1.0$ & $16.6(17.4)$ & $20.4(17.8)$ & $12.3(16.4)^{*}$ & 0.659 \\
\hline \multicolumn{6}{|c|}{ Inflammatory molecular markers } \\
\hline Presepsin, $\times 10^{2} \mathrm{pg} / \mathrm{mL}$ & $<3.14$ & $19.9(36.2)$ & $32.9(46.2)$ & $5.03(4.64)^{* *}$ & 0.887 \\
\hline $\mathrm{PCT}, \mathrm{ng} / \mathrm{mL}$ & $<0.046$ & $28.3(66.9)$ & $51.6(85.6)$ & $2.53(11.8)^{* *}$ & 0.904 \\
\hline $\mathrm{IL}-6, \times 10^{3} \mathrm{pg} / \mathrm{mL}$ & $<0.0034$ & $36.9(134.2)$ & $70.3(179.8)$ & $0.10(0.13)^{* *}$ & 0.893 \\
\hline $\mathrm{CRP}, \mathrm{mg} / \mathrm{dL}$ & $\leqq 0.2$ & $9.88(10.4)$ & $14.9(10.5)$ & $3.93(6.73)^{* *}$ & 0.852 \\
\hline WBC count, $\times 10^{3} / \mu \mathrm{L}$ & 3.5 to 9.1 & $12.3(6.94)$ & $12.3(8.57)$ & $12.3(4.64)$ & 0.503 \\
\hline
\end{tabular}

AT, antithrombin; AUC, area under the curve; CRP, C-reactive protein; IL, interleukin; PC, protein C; PT-INR, prothrombin time-international normalized ratio; PTC, procalcitonin; ROC, receiver-operating curve; SD, standard deviation; TM, thrombomodulin; WBC, white blood cell.

${ }^{*} P<.05 ;{ }^{* *} P<.01$ vs. Sepsis group.

$\mathrm{PC}<45 \%$; (2) mild $(\mathrm{n}=28)$, presepsin $<650 \mathrm{pg} / \mathrm{mL}$ and $\mathrm{PC}>45 \%$, or $650<$ presepsin $<900 \mathrm{pg} / \mathrm{mL}$ and $\mathrm{PC}>55 \%$; (3) moderate $(\mathrm{n}=26)$, ranges between those of the severe and mild groups (Figure 1A).

The 28-day all-cause mortality of sepsis-induced DIC patients was significantly higher than that of patients who did not meet the criteria (Table 6). In this study, the sensitivity, specificity, positive predictive value and negative predictive value of the sepsis-induced DIC criteria were $80.7 \%, 87.5 \%, 90.7 \%$ and $75.0 \%$, respectively (Table 7).

\section{Illness severity according to the classification of} sepsis-induced DIC

We propose the sepsis-induced DIC diagnostic panel as a clinically useful numerical representation of the results

Table 4 Biomarkers of the whole population and stratified according to the presence or absence of DIC

\begin{tabular}{|c|c|c|c|c|c|}
\hline \multirow[t]{3}{*}{ Biomarker } & \multirow{3}{*}{$\begin{array}{l}\text { Normal } \\
\text { range }\end{array}$} & \multirow{3}{*}{$\begin{array}{l}\begin{array}{l}\text { Overall } \\
\text { population }\end{array} \\
\text { Mean (SD) }\end{array}$} & \multicolumn{3}{|c|}{ DIC } \\
\hline & & & Yes $(n=43)$ & No $(n=39)$ & ROC analysis \\
\hline & & & Mean (SD) & Mean (SD) & AUC \\
\hline \multicolumn{6}{|c|}{ Coagulation and fibrinolysis molecular markers } \\
\hline AT activity, \% & 80 to 130 & $71.9(28.1)$ & $55.2(22.5)$ & $84.9(25.2)^{* *}$ & 0.807 \\
\hline PC activity, \% & 70 to 150 & $55.2(34.6)$ & $31.1(18.8)$ & $73.8(32.4)^{* *}$ & 0.877 \\
\hline $\mathrm{TM}, \mathrm{U} / \mathrm{mL}$ & $<22$ & $6.02(6.19)$ & $8.69(8.61)$ & $4.11(2.16)^{* *}$ & 0.730 \\
\hline Platelet counts, $\times 10^{4} / \mu \mathrm{L}$ & 13.0 to 36.9 & $17.5(10.7)$ & $10.6(6.45)$ & $22.9(10.4)^{* *}$ & 0.859 \\
\hline PT-INR & 0.85 to 1.15 & $1.63(1.04)$ & $1.83(0.92)$ & $1.48(1.10)^{* *}$ & 0.795 \\
\hline D -dimer, $\mathrm{ng} / \mathrm{mL}$ & $\leqq 1.0$ & $16.6(17.4)$ & $27.7(18.3)$ & $7.98(10.6)^{* *}$ & 0.844 \\
\hline \multicolumn{6}{|c|}{ Inflammatory molecular markers } \\
\hline Presepsin, $\times 10^{2} \mathrm{pg} / \mathrm{mL}$ & $<3.14$ & $19.9(36.2)$ & $32.5(44.4)$ & $10.0(24.5)^{* *}$ & 0.808 \\
\hline $\mathrm{PCT}, \mathrm{ng} / \mathrm{mL}$ & $<0.046$ & $28.3(66.9)$ & $56.0(92.1)$ & $6.55(18.9)^{* *}$ & 0.785 \\
\hline $\mathrm{IL}-6, \times 10^{3} \mathrm{pg} / \mathrm{mL}$ & $<0.0034$ & $36.9(134.2)$ & $77.6(195.7)$ & $5.13(16.7)^{* *}$ & 0.765 \\
\hline $\mathrm{CRP}, \mathrm{mg} / \mathrm{dL}$ & $\leqq 0.2$ & $9.88(10.4)$ & $12.4(10.7)$ & $7.92(9.93)^{*}$ & 0.650 \\
\hline WBC count, $\times 10^{3} / \mu \mathrm{L}$ & 3.5 to 9.1 & $12.3(6.94)$ & $11.7(6.83)$ & $12.8(7.10)$ & 0.528 \\
\hline
\end{tabular}

AUC, area under the curve; AT, antithrombin; CRP, C-reactive protein; IL, interleukin; PC, protein C; PTC, procalcitonin; PT-INR, prothrombin time-international normalized ratio; $R O C$, receiver-operating curve; $S D$, standard deviation; $T M$, thrombomodulin; WBC, White blood cell.

${ }^{*} P<.05 ;{ }^{* *} P<.01$ vs. Sepsis group. 
Table 5 Cut-off values of each biomarker stratified by the presence or absence of sepsis and DIC

\begin{tabular}{llllllll}
\hline Biomarker & \multicolumn{3}{c}{ Sepsis } & & \multicolumn{3}{c}{ DIC } \\
\cline { 2 - 4 } \cline { 6 - 7 } & Cut-off value & Sensitivity & Specificity & & Cut-off value & Sensitivity & Specificity \\
\hline Presepsin, $\times 10^{2} \mathrm{pg} / \mathrm{mL}$ & 647 & $93.0 \%$ & $76.3 \%$ & 899 & $83.3 \%$ & $78.3 \%$ \\
PC activity, \% & 47 & $77.5 \%$ & $81.1 \%$ & 55 & $91.1 \%$ & $72.7 \%$ \\
\hline
\end{tabular}

DIC, disseminated intravascular coagulation; PC, protein C.

from our multi-marker panel, which includes presepsin and PC panel testing. In addition, to evaluate the diagnostic accuracy of this panel, we investigated whether this panel was able to stratify patients according to the risks of sepsis and DIC as well as physiological severity, degree of organ failure and mortality (Table 8 ). When patients were classified according to sepsis-induced DIC severity, the severity increased significantly with increasing positive rates of sepsis and JAAM DIC. In addition, JAAM DIC, APACHE II and SOFA scores increased significantly with increasing severity $(P<.0001)$ (Table 8$)$. Significant differences in JAAM DIC, APACHE II and SOFA scores were observed between the mild and moderate groups $(P<.0001)$ as well as between the mild and severe groups $(P<.0001)$. Moreover, DIC and SOFA scores differed significantly between the moderate and severe groups (DIC $P<.01$; SOFA score $P<.05$ ).

\section{Discussion}

Sepsis is the most common cause of death in hospitalized patients and affects $>18$ million people worldwide; its incidence is expected to increase by $1 \%$ annually [20]. The mortality of patients who meet the severe sepsis criteria in the first $24 \mathrm{~h}$ after admission to the intensive care unit is 30 to $40 \%$ before intensive care unit discharge. Moreover, 45 to $50 \%$ of these patients die during their hospital stay $[10,12,21]$. In sepsis patients, bacterial products and cytokines also activate coagulation by increasing tissue factor (TF) synthesis and preventing fibrinolysis by increasing the level of Plasminogen Activator Inhibitor Type-1 (PAI-1). Sepsis is frequently complicated with DIC, which arises from fibrin accumulation in small vessels and occlusion of capillaries with microthrombi [22]. Activation of coagulation that arises from sepsis is accompanied by impaired function of major anticoagulant mechanisms including antithrombin, the PC tissue factor pathway inhibitor system and fibrinolysis [23,24]. Proinflammatory cytokines and other mediators are capable of activating the coagulation system and down-regulating important physiological anticoagulant pathways [25]. These processes collectively result in increased levels of intravascular fibrin and the formation of microvascular thrombosis and, thus, ischemic multiple organ dysfunctions leading to necrosis [26].

DIC is associated with high mortality in patients with severe sepsis. The results of this study indicate the 28-day all-cause mortality of sepsis-induced DIC patients meeting the sepsis and JAAM DIC criteria was significantly higher than that of patients who did not meet these criteria (Table 6). Although the effectiveness of anticoagulant therapy in septic patients remains controversial, some studies suggest that rapid diagnosis and early treatment of DIC improve outcomes for these patients. In particular, therapeutic intervention directly against coagulation and inflammation in DIC associated with severe sepsis is effective [8,27]. Furthermore, it is generally accepted that early aggressive treatment of the underlying disease is important.
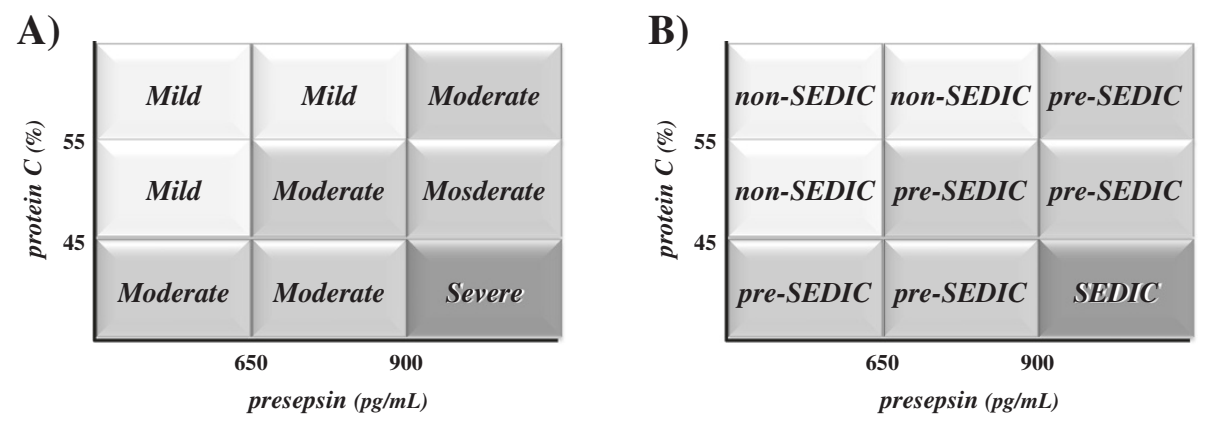

Figure 1 Severity and classification of sepsis-induced DIC. A) Severity of sepsis-induced DIC. Patients were classified into the following three groups according to presepsin and PC levels: (1) severe: presepsin $>900 \mathrm{pg} / \mathrm{mL}$ and $\mathrm{PC}<45 \%$; (2) mild: presepsin $<650 \mathrm{pg} / \mathrm{mL}$ and PC $>45 \%$, or $650<$ presepsin $<900 \mathrm{pg} / \mathrm{mL}$ and PC >55\%; (3) moderate: parameters between the ranges of severe and mild. B) Classification of sepsis-induced DIC (SEDIC) criteria. The categories described in Figure 1A were classified as follows: (1) severe, SEDIC; (2) moderate, pre-SEDIC; (3) mild, non-SEDIC. DIC, disseminated intravascular coagulation; PC, protein C. 
Table 6 Comparison of 28-day all-cause mortality

\begin{tabular}{llll}
\hline Diagnosis & \multicolumn{2}{l}{ 28-day all-cause mortality } & P-value \\
\cline { 2 - 3 } & Negative & Positive & \\
\hline JAAM DIC criteria & $6.5 \%(3 / 46)$ & $30.6 \%(11 / 36)$ & .0041 \\
Sepsis criteria & $7.7 \%(3 / 39)$ & $25.6 \%(11 / 43)$ & .0316 \\
JAAM DIC criteria + sepsis criteria & $7.1 \%(4 / 56)$ & $38.5 \%(10 / 26)$ & .0005 \\
\hline
\end{tabular}

JAAM, Japanese Association for Acute Medicine; DIC, disseminated intravascular coagulation.

In this study, we proposed new diagnostic criteria for sepsis-induced DIC. We assembled a cohort of patients with $\geq 1$ SIRS criterion and investigated a series of biomarkers with the overall goal of creating a panel capable of diagnosing sepsis-induced DIC. Using an innovative approach to establish clinical utility, we created a panel of biomarkers that could provide clinicians with a tangible estimate of the increased risks of sepsis and DIC. The present results indicate that the optimal biomarkers for identifying sepsis-induced DIC are presepsin and $\mathrm{PC}$, which represent inflammatory, and coagulation and fibrinolysis molecular markers, respectively. Presepsin and PC were obviously superior biomarkers for evaluating sepsis and DIC, respectively. This panel is biologically plausible as it incorporates biomarkers involved in key components of the pathophysiology of sepsis and DIC, including infection (presepsin) and activation of coagulation (PC). Moreover, we created new sepsis-induced DIC diagnostic criteria (Figure 1A), which included presepsin $>900 \mathrm{pg} / \mathrm{mL}$ and $\mathrm{PC}<45 \%$. This multi-marker approach offers a distinct mechanistic advantage over single-marker approaches.

Presepsin is a $13-\mathrm{kDa}$ protein that is a truncated Nterminal fragment of CD14, the receptor for lipopolysaccharide (LPS)/LPS-binding protein (LBP) complexes $[28,29]$. Its levels specifically increase in the blood of septic patients. The measurement of presepsin concentrations is reported to be useful for the diagnosis of sepsis, evaluating the severity of sepsis, and monitoring clinical responses to therapeutic interventions [30-34]. Most recently, multicenter clinical studies reported that presepsin is the most valuable predictive marker of sepsis between PCT and IL-6, and is superior to blood culture [35]. Our results corroborate the notion that presepsin is currently the most valuable predictive marker of sepsis. In addition, our results indicate that presepsin is the best predictive marker of DIC compared to other inflammatory molecular markers, including PCT, IL-6 and CRP.
Coagulation activation with subsequent diffuse intravascular fibrin deposition is implicated as an etiological factor in multiple organ dysfunction syndromes in patients with sepsis as well as in transplant and trauma patients [36]. Septic shock progression is associated with even greater mortality rates, ranging from $50 \%$ to $70 \%[37,38]$. The PC system plays a crucial role in the control of microvascular coagulation and inflammation; it is one of the basic regulatory systems of homeostasis, as it has potent anticoagulant, profibrinolytic and anti-inflammatory properties $[39,40]$. PC is converted into activated PC (APC) under the formation of thrombin-thrombomodulin complexes with endothelial PC receptors (EPCRs) in the presence of protein S. Normal levels of circulating PC range from 2,800 to $5,600 \mathrm{ng} / \mathrm{mL}$ (80 to $140 \%$ ), and the protein has a 10-h half-life. In contrast, APC has normal circulating levels from 1 to $3 \mathrm{ng} / \mathrm{mL}$ and a 20-minute half-life [39-42]. Activated PC inactivates coagulation factors Va and VIIIa and neutralizes the effects of PAI-1 [43-45]. In addition, APC is capable of direct anti-inflammatory activity that reduces cytokine production (TNF, migration inhibitory factor (MIF)), thereby inhibiting the adhesion of leukocytes to the blood vessel endothelium $[39,40,45]$. As a result of all of the above mentioned mechanisms, APC significantly reduces the processes of microvascular thrombosis and endothelial dysfunction [46]. Numerous studies demonstrate depressed PC concentrations in both pediatric and adult septic patients are associated with increased morbidity and mortality [47-49]. The present study indicates that PC is more useful for evaluating DIC compared to other coagulation and fibrinolysis molecular markers.

These proposed criteria are useful for the diagnosis of sepsis-induced DIC with extremely high precision (AUC: approximately 0.9$)$. Since the cutoff point for these criteria yielded the optimal sensitivity and specificity $(80.7 \%$ and $87.5 \%$, respectively), they were able to identify patients who likely developed sepsis-induced DIC. The severity of patients' condition (DIC, APACHE II and SOFA scores) differed significantly not only between the mild and severe groups, but also between the mild and moderate groups. The severity of these criteria allows the differentiation of patients with respect to DIC severity, physiological illness (APACHE II), multiple organ failure (SOFA) and mortality. Besides the severe group, treatment should be ready to be initiated anytime in the moderate group.

In this study, we diagnosed DIC using the JAAM DIC diagnostic criteria. The JAAM DIC study group retro-

Table 7 Sensitivity, specificity, positive predictive value and negative predictive value of sepsis-induced DIC criteria

\begin{tabular}{lllll}
\hline Diagnosis & Sensitivity & Specificity & Negative predicative value & Positive predicative value \\
\hline Sepsis-induced DIC criteria & $80.7 \%(21 / 26)$ & $87.5 \%(49 / 56)$ & $90.7 \%(21 / 28)$ & $75.0 \%(49 / 54)$ \\
\hline
\end{tabular}

DIC, disseminated intravascular coagulation. 
Table 8 Sepsis-induced DIC classification according to sepsis and DIC rates, diagnostic scores, and 28-day all-cause mortality

\begin{tabular}{|c|c|c|c|c|}
\hline \multirow[t]{3}{*}{ Biomarker } & \multicolumn{3}{|c|}{ Sepsis-induced DIC } & \multirow[t]{3}{*}{$P$-value } \\
\hline & Mild & Moderate & Severe & \\
\hline & $(n=28)$ & $(n=26)$ & $(n=28)$ & \\
\hline Sepsis (\%) & 10.7 & $61.5^{* *}$ & $88.9^{* * \#}$ & $<.0001$ \\
\hline JAAM DIC (\%) & 3.57 & $42.3^{* *}$ & $85.7^{* * \# \#}$ & $<.0001$ \\
\hline JAAM DIC score (SD) & 1.61 & $3.46(1.3)^{* *}$ & $5.21(1.7)^{* * \# \#}$ & $<.0001$ \\
\hline APACHE \| score (SD) & 12.9 & $21.8(7.8)^{* *}$ & $23.5(10.6)^{* *}$ & $<.0001$ \\
\hline SOFA score (SD) & 3.64 & $8.00(3.4)^{* *}$ & $9.7(3.5)^{* * \#}$ & $<.0001$ \\
\hline 28-day all-cause mortality (\%) & 7.14 & 15.4 & 28.6 & 0.0994 \\
\hline
\end{tabular}

spectively analyzed patients with sepsis complicated with DIC (DIC diagnosed according to the JAAM DIC scoring system) using databases from two previous multicenter studies $[14,50]$. They tested the hypothesis that the JAAM DIC scoring system constitutes a continuum dependent on the International Society on Thrombosis and Haemostasis (ISTH) overt DIC (DIC diagnosed according to the ISTH overt DIC scoring system) and that the JAAM DIC scoring system can predict full-blown DIC in a group of patients associated with systemic inflammation caused by infection. In other words, JAAM DIC with a stressed but compensated hemostatic system continuously progresses to ISTH overt DIC with a stressed but decompensated hemostatic system [51]. When JAAM DIC patients meet the ISTH overt DIC criteria, the risks of multiple organ dysfunction syndrome (MODS) and death are increased approximately 1.5 times. Therefore, the JAAM DIC scoring system is useful for determining patients with sepsis at a stage of stressed but compensated DIC [6].

This study has some limitations that should be noted. This study was a small, prospective, single-center, observational study. The present results suggest that there is no significant association between the severity of sepsis-induced DIC classification (severe, moderate and mild) and mortality. However, we have already initiated a validation study and planned a prospective multicenter study.

\section{Conclusion}

The diagnostic criteria proposed herein are very simple, easy to employ and can be used in intensive care units as a point-of-care test. In addition, this scoring system is useful for the early treatment of sepsis-induced DIC in critical care settings. We also propose the new diagnostic criteria of sepsis-induced DIC termed "SEDIC" with the following categories: severe, SEDIC; moderate, pre-SEDIC; and mild, non-SEDIC (Figure 1B).

\section{Key messages}

- We proposed new diagnostic criteria for sepsis-induced DIC.

- The optimal two-marker panel for sepsis-induced DIC comprises the following: (1) presepsin, an inflammatory biomarker and (2) protein $\mathrm{C}$, a coagulation marker.

- The new sepsis-induced DIC diagnostic criteria were defined as the following three groups: (1) severe, presepsin $>900 \mathrm{pg} / \mathrm{mL}$ and $\mathrm{PC}<45 \%$; (2) mild, presepsin $<650 \mathrm{pg} / \mathrm{mL}$ and $\mathrm{PC}>45 \%$, or $650<$ presepsin $<900 \mathrm{pg} / \mathrm{mL}$ and $\mathrm{PC}>55 \%$; and (3) moderate, ranges between those of the severe and mild groups.

- The severity of sepsis-induced DIC criteria proposed herein allows the discrimination of patients who have severe status according to DIC, physiological illness (APACHE II), multiple organ failure (SOFA) and mortality.

\section{Abbreviations}

ACCP: American College of Chest Physicians; APACHE: Acute Physiology and Chronic Health Evaluation; APC: activated protein C; AT: antithrombin; AUC: area under the curve; CLEIA: chemiluminescent enzyme immunoassay; CRP: C-reactive protein; DIC: disseminated intravascular coagulation; ED: emergency department; IL-6: interleukin-6; INR: international normalized ratio; ISI: International Sensitivity Index; ISTH: International Society on Thrombosis and Haemostasis; JAAM: Japanese Association for Acute Medicine; PAl-1: Plasminogen Activator Inhibitor Type-1; PC: protein C; $\mathrm{PCT}$ : procalcitonin; $\mathrm{PT}$ : prothrombin time; ROC: receiver-operating curve; SCCM: Society of Critical Care Medicine; SD: standard deviation; SEDIC: sepsis-induced disseminated intravascular coagulation; SIRS: systemic inflammatory response syndrome; SOFA: sequential organ failure score; TM: thrombomodulin; WBC: White blood cell count.

\section{Competing interests}

All authors declare that they have no competing interests.

\section{Authors' contributions}

$\mathrm{HI}$ contributed to the study design, analysis, interpretation of the results, drafting of the manuscript and critical revisions of the manuscript for intellectual content. TN and AM were involved in data acquisition and carried out the immunoassays. YN, YI and JT acquired data and YN performed the statistical analysis. TU participated in the study design, 
development and methodology, and helped to draft the manuscript. All authors read and approved the final manuscript.

\section{Acknowledgments}

We sincerely thank Mr. Yoshikazu Okamura of the Mitsubishi Chemical Medience Corporation for his advice regarding this research.

Received: 8 August 2013 Accepted: 9 January 2014

Published: 20 January 2014

\section{References}

1. Moore LJ, Moore FA, Todd SR, Jones SL, Turner KL, Bass BL: Sepsis in general surgery: the 2005-2007 national surgical quality improvement program perspective. Arch Surg 2010, 145:695-700.

2. Remick DG: Pathophysiology of sepsis. Am J Pathol 2007, 170:1435-1444

3. Dellinger RP, Levy MM, Rhodes A, Annane D, Gerlach H, Opal SM, Sevransky JE, Sprung CL, Douglas IS, Jaeschke R, Osborn TM, Nunnally ME, Townsend SR, Reinhart K, Kleinpell RM, Angus DC, Deutschman CS, Machado FR, Rubenfeld GD, Webb SA, Beale RJ, Vincent JL, Moreno R: Surviving Sepsis Campaign: International Guidelines for Management of Severe Sepsis and Septic Shock: 2012. Crit Care Med 2013, 41:580-637.

4. American College of Chest Physicians/Society of Critical Care Medicine Consensus Conference: definitions for sepsis and organ failure and guidelines for the use of innovative therapies in sepsis. Crit Care Med 1992, 20:864-874.

5. Ogura H, Gando S, Iba T, Eguchi Y, Ohtomo Y, Okamoto K, Koseki K, Mayumi T, Murata A, Ikeda T, Ishikura H, Ueyama M, Kushimoto S, Saitoh D, Endo S, Shimazaki S: SIRS-associated coagulopathy and organ dysfunction in critically ill patients with thrombocytopenia. Shock 2007, 28:411-417.

6. Gando S, Kameue T, Nanzaki S, Nakanishi Y: Disseminated intravascular coagulation is a frequent complication of systemic inflammatory response syndrome. Thromb Haemost 1996, 75:224-228.

7. Range-Frausto MS, Pittet D, Costigan M, Hwang T, Davis CS, Wenzel RP: The natural history of the systemic inflammatory response syndrome (SIRS). A prospective study. JAMA 1995, 273:117-123.

8. Dhainaut JF, Yan SB, Joyce DE, Pettilä V, Basson B, Brandt JT, Sundin DP, Levi M: Treatment effects of drotrecogin alfa (activated) in patients with severe sepsis with or without overt disseminated intravascular coagulation. J Thromb Haemost 2004, 2:1924-1933.

9. Kienast J, Juers M, Wiedermann CJ, Hoffmann JN, Ostermann H, Strauss R, Keinecke HO, Warren BL, Opal SM: Treatments effects of high-dose antithrombin without concomitant heparin in patients with severe sepsis with or without disseminated intravascular coagulation. J Thromb Haemost 2006, 4:90-97.

10. Beale R, Reinhart K, Brunkhorst FM, Dobb G, Levy M, Martin G, Martin C, Ramsey G, Silva E, Vallet B, Vincent JL, Janes JM, Sarwat S, Williams MD: Promoting Global Research Excellence in Severe Sepsis (PROGRESS): lessons from an international sepsis registry. Infection 2009, 37:222-232.

11. Dellinger RP, Levy MM, Carlet JM, Bion J, Parker MM, Jaeschke R, Reinhart K, Angus DC, Brun-Buisson C, Beale R, Calandra T, Dhainaut JF, Gerlach H, Harvey M, Marini JJ, Marshall J, Ranieri M, Ramsay G, Sevransky J, Thompson BT, Townsend S, Vender JS, Zimmerman JL, Vincent JL: Surviving Sepsis Campaign: international guidelines for management of severe sepsis and septic shock: 2008. Crit Care Med 2008, 36:296-327.

12. Vincent JL, Sakr Y, Sprung CL, Ranieri VM, Reinhart K, Gerlach H, Moreno R, Carlet J, Le Gall JR, Payen D: Sepsis in European intensive care units: results of the SOAP study. Crit Care Med 2006, 34:344-353.

13. Wittebole $X$, Castanares-Zapatero D, Laterre PF: Toll-like receptor 4 modulation as a strategy to treat sepsis. Mediators Inflamm 2010, 2010:568396.

14. Gando S, Iba T, Eguchi Y, Ohtomo Y, Okamoto K, Koseki K, Mayumi T, Murata A, Ikeda T, Ishikura H, Ueyama M, Ogura H, Kushimoto S, Saitoh D, Endo S, Shimazaki S: A multicenter, prospective validation of disseminated intravascular coagulation diagnostic criteria for critically ill patients: comparing current criteria. Crit Care Med 2006, 34:625-631.

15. Knaus WA, Draper EA, Wagner DP, Zimmerman JE: APACHE II: a severity of disease classification system. Crit Care Med 1985, 13:818-829.

16. Vincent JL, de Mendonça A, Cantraine F, Moreno R, Takala J, Suter PM, Sprung CL, Colardyn F, Blecher S: Use of the SOFA score to assess the incidence of organ dysfunction/failure in intensive care units: results of a multicenter, prospective study. Working group on "sepsis-related problems" of the European Society of Intensive Care Medicine. Crit Care Med 1998, 26:1793-1800

17. Kurihara T, Yanagida A, Yokoi H, Koyata A, Matsuya T, Ogawa J, Okamura Y, Miyamoto D: Evaluation of cardiac assays on a benchtop chemiluminescent enzyme immunoassay analyzer, PATHFAST. Anal Biochem 2008, 375:144-146.

18. Okamura Y, Yokoi H: Development of a point-of-care assay system for measurement of presepsin (sCD14-ST). Clin Chim Acta 2011, 412:2157-2161.

19. Hanley JA, McNeil BJ: The meaning and use of the area under a receiver operating characteristic (ROC) curve. Radiology 1982, 143:29-36.

20. Ulloa L, Tracey KJ: The "cytokine profile": a code for sepsis. Trends Mol Med 2005, 11:56-63.

21. Padkin A, Goldfrad C, Brady AR, Young D, Black N, Rowan K: Epidemiology of severe sepsis occurring in the first $24 \mathrm{hrs}$ in the intensive care unit in England, Wales, and Northern Ireland. Crit Care Med 2003, 31:2332-2338.

22. Peters K, Unger RE, Brunner J, Kirkpatrick CJ: Molecular basis of endothelial dysfunction in sepsis. Cardiovasc Res 2003, 60:49-57.

23. van der Poll T, Levi M: Crosstalk between inflammation and coagulation: the lessons of sepsis. Curr Vasc Pharmacol 2012, 10:632-638.

24. Cohen J: The immunopathogenesis of sepsis. Nature 2002, 420:885-891.

25. Levi M, van der Poll T: Inflammation and coagulation. Crit Care Med 2010, 38:S26-S34.

26. Zeerleder S, Hack CE, Wuillemin WA: Disseminated intravascular coagulation in sepsis. Chest 2005, 128:2864-2875.

27. Wada H, Wakita Y, Nakase T, Shimura M, Hiyoyama K, Nagaya S, Mori Y, Shiku $\mathrm{H}$ : Outcome of disseminated intravascular coagulation in relation to the score when treatment was begun. Mie DIC Study Group. Thromb Haemost 1995, 74:848-852.

28. Furusako S, Shirakawa K: Methods for detecting human low molecular weight CD14. United States patent; 2008:US7465547 B2.

29. Furusako S, Shirakawa K, Hirose J: Soluble CD14 antigen. United States patent; 2009:US7608684 B2.

30. Yaegashi Y, Shirakawa K, Sato N, Suzuki Y, Kojika M, Imai S, Takahashi G, Miyata M, Furusako S, Endo S: Evaluation of a newly identified soluble CD14 subtype as a marker for sepsis. J Infect Chemother 2005, 11:234-238.

31. Kojika M, Takahashi G, Matsumoto N, Kikkawa T, Hoshikawa K, Shioya N, Shibata S, Suzuki Y, Aoki H, Shirakawa K, Endo S: Serum levels of soluble CD14 subtype reflect the APACHE II and SOFA Scores. Med Postgrad 2010, 48:46-50.

32. Takahashi G, Suzuki Y, Kojika M, Matsumoto N, Shozushima T, Makabe H, Yamada Y, Shioya N, Shibata S, Shirakawa K, Endo S: Evaluation of responses to IVIG therapy in patients with severe sepsis and septic shock by soluble CD14 subtype monitoring. Med Postgrad 2010, 48:19-24.

33. Shozushima T, Takahashi G, Matsumoto N, Kojika M, Okamura Y, Endo S: Usefulness of presepsin (sCD14-ST) measurements as a marker for the diagnosis and severity of sepsis that satisfied diagnostic criteria of systemic inflammatory response syndrome. J Infect Chemother 2011, 17:764-769.

34. Mussap M, Noto A, Fravega M, Fanos V: Soluble CD14 subtype presepsin (sCD14-ST) and lipopolysaccharide binding protein (LBP) in neonatal sepsis: new clinical and analytical perspectives for two old biomarkers. J Matern Fetal Neonatal Med 2011, 24:12-14.

35. Endo S, Suzuki $Y$, Takahashi G, Shozushima T, Ishikura H, Murai A, Nishida T, Irie $Y$, Miura M, Iguchi H, Fukui Y, Tanaka K, Nojima T, Okamura Y: Usefulness of presepsin in the diagnosis of sepsis in a multicenter prospective study. J Infect Chemother 2012, 18:891-897.

36. Levi M, van der Poll T, ten Cate H, van Deventer $S$ J: The cytokine-mediated between coagulant and anticoagulant mechanisms in sepsis and endotoxemia. Eur J Clin Ivest 1997, 27:3-9.

37. Farthmann EH, Schoffel U: Principles and limitations of operative management of intaabdominal infections. World J Surg 1990, 14:210-217

38. Garcia-Sabrido JM, Talado JM, Christou NV: Treatment of severe inta-abdominal sepsis and/or necrotic foci by an open abdomen approach: zipper and zipper-mesh techniques. Arch Surg 1988, 123:152-156.

39. Bernard GR, Hartman DL, Helterbrand JD, Fisher CJ: Recombinant human activated protein $\mathrm{C}$ (rhAPC) produces a trend toward improvement in morbidity and 28-day survival in patients with severe sepsis. Crit Care Med 1999, 27:S33-S35.

40. Bernard GR, Macias WL, Joyce DE, Williams MD, Bailey J, Vincent JL: Safety assessment of drotrecogin alfa (activated) in the treatment of adult patients with severe sepsis. Crit Care 2003, 7:155-163.

41. Yan SB, Dhainaut JF: Activated protein $C$ versus protein $C$ in severe sepsis. Crit Care Med 2001, 29:S69-S74. 
42. Dhainaut JF, Yan SB, Cariou A, Mira JP: Soluble thrombomodulin, plasma-derived unactivated protein $C$, and recombinant human activated protein C in sepsis. Crit Care Med 2002, 30:\$318-S323.

43. Bernard GR, Vincent JL, Laterre PF: Efficiacy and safety of recombinant human activated protein C for severe sepsis. N Engl J Med 2001, 344:699-709.

44. Mesters RM, Helterbrand J, Utterback BG, Yan B, Chao YB, Fernandez JA, Griffin $J H$, Hartman DL: Prognostic value of protein $C$ concentrations in neutropenic patients at high risk of severe septic complications. Crit Care Med 2000, 28:2209-2216.

45. Marlar RA, Endres BJ, Miler C: Serial studies of protein C and its plasma inhibitor in patients with DIC. Blood 1985, 66:59-63.

46. Jonge $E$, Levi M, Van der Poll T: Natural anticoagulants in disseminated intravascular coagulation and sepsis. In Yearbook of Intensive Care and Emergency Medicine. Edited by Vincent JL. Berlin: Springer-Verlag; 2001:348-352.

47. Macias WL, Nelson DR: Severe protein C deficiency predicts early death in severe sepsis. Crit Care Med 2004, 32:S223-S228.

48. Fisher CJ Jr, Yan SB: Protein C levels as a prognostic indicator of outcome in sepsis and related diseases. Crit Care Med 2000, 28:S49-S56.

49. Macias WL, Derchak PA: Coagulopathy may occur before the clinical diagnosis of organ dysfunction. Crit Care Med 2002, 30:5100.

50. Gando S, Saitoh D, Ogura H, Mayumi T, Koseki K, Ikeda T, Ishikura H, Iba T, Ueyama M, Eguchi Y, Ohtomo Y, Okamoto K, Kushimoto S, Endo S, Shimazaki S: Natural history of disseminated intravascular coagulation diagnosed based on the newly established diagnostic criteria for critically ill patients: results of a multicenter, prospective survey. Crit Care Med 2008, 36:145-150

51. Taylor FB Jr, Toh CH, Hoot WK, Wada H, Levi M: Toward definition, clinical and laboratory criteria, and a scoring system for disseminated intravascular coagulation. Thromb Haemost 2001, 86:1327-1330.

doi:10.1186/cc13700

Cite this article as: Ishikura et al:: New diagnostic strategy for sepsisinduced disseminated intravascular coagulation: a prospective single-center observational study. Critical Care 2014 18:R19.

\section{Submit your next manuscript to BioMed Central and take full advantage of:}

- Convenient online submission

- Thorough peer review

- No space constraints or color figure charges

- Immediate publication on acceptance

- Inclusion in PubMed, CAS, Scopus and Google Scholar

- Research which is freely available for redistribution 